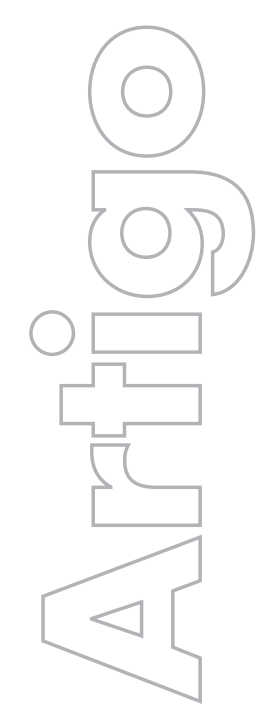

revista

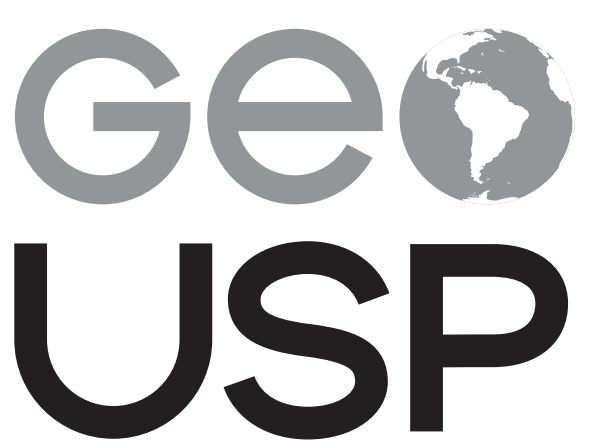

espaço e tempo

Volume $21 \cdot n^{\circ} 2$ (2017)

ISSN 2179-0892

\section{Do urbanismo unitário à} crítica ao urbanismo: um percurso sobre a cidade e o urbano na Internacional Situacionista

Glauco Roberto Gonçalves UFG

p. $518-530$

Como citar este artigo:

GONÇALVES, G. R. Do urbanismo unitário à crítica ao urbanismo: um percurso sobre a cidade e o urbano na Internacional Situacionista. Geousp - Espaço e Tempo (Online), v. 21, n. 2, p. 518-530, agosto. 2017. ISSN 2179-0892.

Disponível em: < http://www.revistas.usp.br/geousp/ article/view/117516>. doi: 10.11606/issn.2179-0892. geousp.2017.117516.

\section{(c) $(1) \circledast$}

Este artigo está licenciado sob a Creative Commons Attribution 4.0 License. 


\title{
Do urbanismo unitário à crítica ao urbanismo: um percurso sobre a cidade e o urbano na Internacional Situacionista
}

\section{Resumo}

A Internacional Situacionista se dedicou com afinco a estudos, práticas e elaborações textuais sobre importantes temas necessários para criticar e transformar radicalmente a vida. Nesse sentido, a cidade e o urbano se destacam nos debates das revistas letristas e situacionistas. Em particular, este texto aborda o conjunto de debates travados por esse grupo no campo sobre o urbano e o urbanismo e procura tecer um percurso histórico constitutivo de compreensão e ação desses temas para letristas e situacionistas. Como indica o próprio título do texto, o movimento vai do processo de proposição de concepções urbanísticas, mais notadamente aquelas voltadas ao Urbanismo Unitário, à crítica radical do urbanismo.

Palavras-chave: Internacional Situacionista. Internacional Letrista. Urbanismo unitário. Geografia urbana. Crítica do urbanismo e do cotidiano.

\section{From Unitary Urbanism to the critique of urbanism: a tour across the concept of city and urban in the Situationist International movement}

\begin{abstract}
The Situationist International have had great dedication on the studies, practices and textual elaborations of important topics necessary to criticize and to radically transform life. In this sense the urban and the cities were highlighted within the Letterist's and Situationist' s magazines' debates. This text approaches the debates presented by these groups in the fields of urban and urbanistic conceptions; it also proposes a constitutive historical path to the way of understanding and action of these issues for the Letterist and Situationist movement. This article's discussion will flow, as shown by the title of the text, from the proposition process of urban planning concepts - most notably those aimed at Unitary Urbanism - to the radical critique of urbanism.
\end{abstract}

Keywords: Situationist International. Letterist International. Unitary Urbanism. Urban Geography. Critique of urbanism and everyday life. 


\section{Introdução}

Este texto é parte da tese de doutorado em Geografia Humana defendida na Faculdade de Filosofia Letras e Ciências Humanas da Universidade de São Paulo em fevereiro de 2016. Para compreender a relação entre imagem e cidade e, cidade como imagem - tema central da tese -, foi detalhadamente estudado o conjunto das publicações situacionistas e letristas, mais notadamente as obras de seus principais autores: Guy Debord e Raoul Vaneigem. Todavia, se este texto - bem como os demais que compõe a tese - é de autoria individual, o processo de estudo dos situacionistas é de caráter coletivo e se deu ao longo de mais de uma década de Grupo de Estudos dos Situacionistas. Esse tem sido realizado no Laboratório de Geografia Urbana da Universidade de São Paulo (Labur, Geousp) com o acompanhamento e a supervisão da professora Amélia Luisa Damiani.

Nós, do Grupo de Estudos sobre os Situacionistas, estamos convictos de que as publicações Internacional Situacionista (IS) e Internacional Letrista (IL) constituem um vigoroso caminho de desvendamento crítico do processo de urbanização da sociedade e nos oferece sólidos instrumentos e ferramentas para a realização de estudos e pesquisas em Geografia Urbana. Prova disto, entre outros exemplos, é a deriva: ${ }^{1}$ uma estratégia de percorrer a cidade proposta pelos situacionistas que tem sido significativamente utilizada em recentes pesquisas de Geografia Urbana. ${ }^{2}$

Para além de instrumentos e ferramentas de trabalho de campo, os textos situacionistas sobre a cidade e o urbano carregam proposições teóricas e metodológicas acerca deste tema e estão relacionados - estabelecendo um diálogo crítico - com a Arquitetura Moderna, com o funcionalismo e com o planejamento urbano.

Neste artigo procura-se resgatar de forma cronológica o percurso constitutivo desse debate dentro da revista Potlatch, publicada e editada pela Internacional Letrista, e da revista Internacional Situacionista, publicada pelo grupo com o mesmo nome. ${ }^{3}$

\section{Do Urbanismo Unitário à crítica ao urbanismo}

No movimento incessante de ideias da IS, a noção de Urbanismo Unitário foi uma aposta que nos primeiros anos do grupo deteve significativa importância. Os situacionistas buscaram um permanente encontro da crítica e da teoria com a prática, e nesse percurso o Urba-

\footnotetext{
1 "A deriva é um modo de comportamento experimental numa sociedade urbana. Além de um modo de ação, é um meio de conhecimento, especialmente no que se refere à psicogeografia e à teoria do Urbanismo Unitário. Os outros meios, como a leitura de fotos aéreas e de mapas, o estudo de estatísticas e de gráficos ou de resultados de pesquisas sociológicas, são teóricos e não têm este lado ativo e direto do qual pertence à deriva experimental. No entanto, é graças a eles que podemos ter uma primeira representação do meio a estudar. E o resultado desse estudo pode, em retorno, modificar essas representações cartográficas e intelectuais no sentido de uma maior complexidade, de um enriquecimento" (Jacques, 2003, p. 80).

2 Ver, por exemplo, Silva (2004).

3 A Internacional Letrista se valeu no pós-Guerra, mais especificamente desde 1954, da publicação semanal intitulada Potlatch, que teve ao todo 29 números. Nessa revista, surgem muitos dos mais relevantes conceitos e propositivas do grupo, tais como a deriva, a psicogeografia e o desvio, além do aprimoramento da crítica radical ao urbanismo e à arquitetura (Urbanismo Unitário), bem como às demais artes. Potlatch teve sua última edição (n. 29) produzida pela recém-criada Internacional Situacionista, fundada na Conferência em Cosio D’ Arroscio, em 1958.

A Internacional Situacionista surge com a junção dos membros da Internacional Letrista ao Movimento Internacional Bauhaus Imaginista (MIBI, formado por Gallizio e Jorn, contrapunha-se à Bauhaus funcionalista), que pode ser considerado oriundo do grupo Cobra (Copenhague, Bruxelas, Amsterdã, 1948-1951, revista homônima). Também merece ser citado aqui o London Psichogeographical Association, que teve relevante participação na formação Situacionista.
} 
nismo Unitário colocou-se como possibilidade de fazer, num projeto urbano, toda a crítica ao funcionalismo e às formas de (não) uso da cidade. A primeira vez que a noção de Urbanismo Unitário aparece em escritos letristas/situacionistas é na ocasião do Congresso de Alba, ${ }^{4}$ onde se encontram pela primeira vez (ao menos "oficialmente") membros da Internacional Letrista, da Bauhaus Imaginista, do antigo grupo Cobra (Copenhague, Bruxelas, Amsterdã, 1948-1951) e pessoas autônomas de variados países (Argélia, Itália, Checoslováquia, Grã-Bretanha, além de França, Holanda, Bélgica e Dinamarca), que dão início a uma organização em comum. Diante dessas pessoas de variadas origens, o então delegado da IL, Gil Wolman, citado em texto coletivo da própria IL, declara:

Camaradas, as crises paralelas que afetam atualmente todos os modos de criação artística são determinantes para um movimento de união, e não se pode conseguir a resolução destas crises senão em uma perspectiva geral. $\bigcirc$ processo de negação e de destruição que se manifesta, com uma velocidade crescente, contra todas as condições velhas da atividade artística é irreversível: e é consequência do aparecimento das possibilidades superiores de ação sobre o mundo [...].

Qualquer crédito que a burguesia venha hoje em dia atribuir às tentativas artísticas fragmentárias, ou deliberadamente retrógradas, a criação não pode ser mantida senão em uma síntese que tende à construção integral de uma atmosfera, de um estilo de vida... Um Urbanismo Unitário - a síntese, anexando arte e técnica, que nós clamamos - deve ser edificada em função de certos valores novos da vida que se trata desde já de se distinguir e de se espalhar (Debord, 1996, p. 247-248). ${ }^{5}$

Nota-se que o aparecimento da noção de Urbanismo Unitário advém, naquele momento, da necessidade de se contrapor à criação artística em todas as suas faces e posta em sua forma individual. $\bigcirc$ Urbanismo Unitário aparece como resposta à arte fragmentária e como possibilidade de atuação e criação, no plano da totalidade do vivido. Em vez de produzir determinados objetos, tratar-se-ia de produzir o espaço inteiro para a arte de viver. No Congresso de Alba, o Urbanismo Unitário sintetizou a possibilidade de ação conjunta dos diferentes grupos de vanguarda, trazia a irradiação de um plano de ação que atacava não só as artes fragmentárias como o funcionalismo, propondo um caminho de transformação do mundo que passava pela cidade. Produzir a cidade era ao mesmo tempo transformar a totalidade do vivido e colocar fim à criação artística realizando-a no cotidiano. A revolução adquiria uma nova forma de ação, que passava irremediavelmente por uma inteiramente nova produção do urbano atrelada à transformação total e profunda da vida cotidiana. Naquele momento, a ideia de um

4 Ver "A Plata-forma de Alba", em Potlatch n. 27 (Debord, 1996). Nota-se a desconstrução da palavra e a ênfase ao debate sobre a forma. Esse encontro, convocado por Gallizio e Jorn e realizado na Itália, pode ser considerado o marco inicial de formulação da IS. Entretanto, é preciso lembrar que, como foi dito em O Urbanismo Unitário no final dos anos 1950 (IS, n. 3, 2004, p. 75), o conceito de Urbanismo Unitário apareceu já nos idos de 1953 e foi divulgado num panfleto de 1956 pelos camaradas de Torino (que viriam ainda a ser a sessão italiana dos Situacionistas), os quais disseram (na revista La Nuova Estampa): "O futuro dos vossos filhos depende de que eles se manifestem em favor do Urbanismo Unitário” (IS, n. 3, 2004, p. 75).

5 Convém salientar que a totalidade das revistas Potlatch foram agrupadas, organizadas e publicadas com esse título por Guy Debord (1996). Assim, os trechos advindos de textos coletivos citados neste artigo tiveram suas referências bibliográficas atribuídas ao organizador da revista, que é também um de seus autores. 
Urbanismo Unitário foi um meio para agregar diferentes grupos e indivíduos autônomos que atuavam na linha de frente da superação artística e das artes, bem como aqueles que atuavam em projetos de transformação da cidade e revolução da vida cotidiana. De modo geral, a noção de Urbanismo Unitário foi o ponto culminante da formação da IS (como se pode ver na citação a seguir) e deu início a um novo momento da organização e da contestação, no qual a cidade e o cotidiano foram centrais na proposta de transformação da vida e realização da arte.

A resolução final do Congresso [de Alba] traduziu um acordo profundo, sob a forma de uma declaração em seis pontos proclamando a "necessidade de uma construção integral de um quadro de vida por um Urbanismo Unitário que deve utilizar o conjunto das artes nos seus limites tradicionais"; "o reconhecimento de uma interdependência essencial entre o Urbanismo Unitário e um estilo de vida a vir..." que pode ser situado "na perspectiva de uma liberação real maior e de uma grande dominação da natureza"; enfim "a unidade de ação entre os signatários e seu programa (o sexto ponto enumera diversas modalidades de uma sustentação recíproca)" (Debord, 1996, p. 248).

O desenrolar da formação situacionista segue sendo relatado em Potlatch e culmina no controle da revista não mais pela IL (dissolvida) e sim pela nascente IS, já a partir da revista n. 30. ${ }^{6}$ É possível afirmar que o Urbanismo Unitário foi a principal formulação prático-teórica na formação da IS. A partir desse momento, o Urbanismo Unitário passa a ser profundamente identificado com a figura de Constant. ${ }^{7} \mathrm{Na}$ revista Potlatch sob controle situacionista aparecem relatos (texto Primeiras maquetes por um urbanismo novo) da exposição feita por Constant no Stedelijk Museum de Amsterdã onde, pela primeira vez, aparecem as maquetes destinadas ao Urbanismo Unitário.

[...] esta exposição pode marcar a passagem, ao interior da produção artística moderna, do objeto-mercadoria sendo suficiente a ele mesmo e cuja função é ser simplesmente observado, ao objeto-projeto cuja valorização mais complexa se convoca a uma ação conduzida, ação de um tipo superior concernente à totalidade da vida (Debord, 1996, p. 287).

Nessa última edição de Potlatch, n. 30, (Debord, 1996) aparece mais um texto destinado ao Urbanismo Unitário, evidenciando que esta ideia foi tida como oportunidade de realização de um projeto mais amplo e total, na medida em que possibilitava ao mesmo tempo pensar e propor um novo modo de viver a cidade e de produzi-la. Assim como de realizar a arte em uma

6 Que, embora tenha sido classificada como n. 1 da nova série, torna-se a última publicação com o nome anterior, dando lugar à revista da IS.

7 Constant Nieuwenhuys foi uma pessoa importante na formação e nos primeiros anos da IS. Advindo do movimento Cobra, participou ativamente da fundação da IS. Era arquiteto e foi se tornando o principal formulador das ideias e proposições do Urbanismo Unitário. Chegou a propor um modelo arquitetônico/urbanístico de Urbanismo Unitário intitulado "Nova Babilônia", no qual um único prédio suspenso por pilares reuniria todas as moradias e demais atividades. A superfície do solo seria mantida sem construção para a livre criação e uso dos habitantes, e as máquinas ocupariam o subsolo. Depois de expulso da IS, na revista n. 5 (IS, 2004) de dezembro de 1960, envolveu-se no que ficou conhecido como movimento Provos de Amsterdã, de significativa e visível influência Situacionista. Também passou a atuar como arquiteto, o que gerou inúmeras críticas e sátiras por parte da IS. 
instância coletiva e contraposta à arte burguesa individual e, ainda, de pôr em curso novos e aprofundados projetos de deriva e de psicogeografia, elevando o lúdico à centralidade da cidade. Por isso, não parece ocasional que o derradeiro texto da Potlatch - "O grande jogo que está por vir" -, escrito por Constant (19598 apud Debord, 1996), seja justamente dedicado à relação entre o urbano e o lúdico. Nele, Constant afirma que "a total falta de soluções lúdicas na organização da vida social impede que o urbano se eleve ao nível de criação [...]".

Ainda nesse texto assinado por Constant (19599 apud Debord, 1996, p. 290), ele deixa claro que:

Os situacionistas exploradores especializados no jogo e no lazer compreendem que o aspecto visual das cidades só tem valor se relacionados com os efeitos psicológicos que possam produzir, efeitos esses que devem ser calculados no total das funções a prever. Nosso conceito de urbanismo não se limita à função, mas também ao uso que delas se faz e se imagina fazer. É claro que esse uso terá de mudar com as condições sociais que o permitem; por isso nossa concepção de urbanismo é dinâmica. Recusamos essa implementação de prédios numa paisagem fixa, que atualmente constrói o novo urbanismo. Ao contrário, pensamos que todo elemento estático e inalterável deve ser evitado, e que o caráter variável ou móbil dos elementos arquitetônicos é condição para uma relação flexível com os acontecimentos que neles serão vividos.

É possível identificar nesse texto um desenrolar daquilo que Wolman expôs na ocasião do Congresso de Alba sobre o Urbanismo Unitário - o urbanismo como chave para juntar ações lúdicas e artísticas voltadas à reinvenção daquilo que ele chamou de "um estilo de vida" -, e que Constant começava a desenvolver. $\bigcirc$ Urbanismo Unitário sugerido por Wolman era aquele que possibilitava a realização da arte e do lúdico na vida num plano de totalidade e, certamente por isso, essa noção adquiriu centralidade no momento de formação da IS. ${ }^{10}$ Vê-se no texto de Constant uma busca por aprofundar tais sugestões de Wolman, entretanto, Constant vai gradativamente rumando em busca de um projeto arquitetural. Os motivos que levam à sua expulsão da IS, pouco tempo depois (menos de dois anos depois desse texto), já podem ser minimamente identificados aqui, visto que seu anseio por desenhar e propor a espacialidade do Urbanismo Unitário reitera unicamente a especialização tecnocrática do arquiteto. Se Constant toma como premissa a necessidade de pôr em curso um urbanismo lúdico e não limitado à função, " nem por isso ele deixa de se encantar com a possibilidade de ser o propositor e criador dessa espacialidade, reiterando todo o fetiche do "arquiteto artista de maquetes vividas". Em suma, o projeto do Urbanismo Unitário sofre, já desde seus primeiros momentos, com Constant, um processo de aproximação da arquitetura como atividade separada e especializada, proposta por um especialista. Constant entende que o Urbanismo Unitário pode ser um caminho frutífero para colocar fim às artes individuais, mas quer produzi-lo como obra de sua autoria.

Parece-me relevante salientar que nesse trecho do texto de Constant os aspectos visuais da cidade são abordados e aceitos pelo que possam vir a produzir. Primeiro, é interessante notar que a imagem da cidade e sua produção já detinham significativa centralidade dentro

8 Constant, B. Le grand jeu à venir. Potlatch, n. 30, jul. 1959.

9 Constant, B. Le grand jeu à venir. Potlatch, n. 30, jul. 1959.

10 "A arte integral, de que tanto se falou, só pode ser realizada no urbanismo", segundo Guy Debord, no Relatório sobre a construção de situações e sobre as condições de organização e de ação da tendência situacionista internacional (Jacques, 2003).

11 Nota-se mais uma vez que o Urbanismo Unitário ganha força também como contraposição ao funcionalismo. 
da arquitetura e do planejamento funcionalista, uma vez que isso merece destaque nas considerações de Constant. Também é importante observar aí a aceitação dos padrões vigentes da arquitetura pelo autor, o qual parece querer manter muitas das realizações da arquitetura daquele momento. É notória a influência funcionalista sobre ele: assim como não nega a produção da cidade em seu teor imagético (desde que produza efeitos psicológicos), ele também não nega a função, querendo partir dela para ampliá-la. De modo que é possível até mesmo afirmar, com base no trecho transcrito acima, que seu Urbanismo Unitário é funcionalista.

Nesse sentido, não parece ocasional que o primeiro número da revista IS traga um texto de Gilles Ivain de 1953 (Formulário para um urbanismo novo) em que todo tédio que reina na cidade mercadoria é evidenciado, bem como o projeto funcionalista é frontalmente atacado. ${ }^{12}$ É bem verdade que esse texto de Ivain também propunha soluções de ordem prática, como a criação de cenários móveis e a casa giratória que acompanha o sol, por exemplo, mas seu foco era atacar a arquitetura do "ócio aborrecedor". Assim, o autor afirma que "Não se trata somente da articulação e da modulação plástica, expressão de beleza passageira, mas de uma modulação influencial que se escreve na curva eterna dos desejos humanos [...]" (IS, n. 1, 2004, p. 20), o que deixa claro, desde o começo, que a preocupação letrista/situacionista com a cidade e seus aspectos arquiteturais passava irremediavelmente pelo debate da forma, da aparência e da beleza dos espaços construídos na cidade que, via de regra, não se colocavam como solução nem como atrativo para uma vida liberta e profunda. $\bigcirc$ texto de Gilles Ivain é muito mais uma crítica ao urbanismo em voga, que disseminava o tédio e impedia o jogo, enfatizando a proliferação do conforto e de objetos enfadonhos em detrimento das situações e do vivido ("Entre o amor e o cesto de lixo automático, a juventude do mundo todo preferiu o cesto de lixo automático" [IS, n. 1, 2004, p. 21]), do que propriamente um formulário para um urbanismo novo, no sentido do projeto urbanístico fechado que Constant passa a desenvolver.

Diante dessas duas concepções diferentes, pode-se dizer, urbanísticas, é possível ver a irradiação das mais variadas ideias que se contradiziam e que estiveram presentes nos primeiros anos da IS, dando mostras de que não se tratava de um grupo coeso e fechado, e de que as formulações de transformação da cidade, da vida e do mundo estavam em curso e não eram fechadas nem acabadas, mas sim contraditórias, abertas e contrapostas. Essas divergências podem ser vistas no texto "Sobre nossos meios e nossas perspectivas" escrito por Constant na revista n. 2 da IS (2004, p. 22), em que são frontalmente atacadas as ideias de Asger Jorn contra o funcionalismo e também as ideias de Gilles Ivain sobre o habitat humano. Nesse texto, Constant faz uma defesa aberta das máquinas, ${ }^{13}$ além de se autodeclarar como representante supremo das ideias situacionistas sobre o Urbanismo Unitário.

12 É curioso, e nada ocasional, que partes desse texto tenham sido excluídas da versão publicada na primeira edição da revista situacionista, visto que eram pesadas as críticas de Ivan a Le Corbusier e aos funcionalistas. $\bigcirc$ momento da primeira revista é o que Debord (1997) chamou de "um passo atrás". Havia membros que detinham certas relações (afetuosas?) com o funcionalismo, o que possivelmente fez com que ficassem de fora as críticas mais vorazes à Arquitetura Moderna e seu principal expoente.

13 Mais um fato que endossará sua condição e classificação como tecnocrata pouco tempo depois. Aliás, o projeto de Urbanismo Unitário de Constant tinha na automação um de seus pilares. Como já dito, o subsolo da Nova Babilônia seria destinado às máquinas, que fariam toda a produção, deixando o solo para ser usado pelas pessoas liberadas do trabalho. No texto Sobre nossos meios e nossas perspectivas, o autor diz: "A máquina é um útil indispensável para todo mundo, inclusive para os artistas, e a indústria é o único meio possível para satisfazer as necessidades da humanidade em escala mundial, incluindo as necessidades estéticas" (IS, n. 2, 2004, p. 54). 
A revista n. 2 da IS (2004) tem uma participação enfática de Constant que, além do texto acima citado, escreveu junto com Debord os onze pontos da "Declaração de Amsterdam", na qual é possível afirmar que o ideário do Urbanismo Unitário atingiu seu ponto máximo no momento em que colocou a possibilidade de construção e realização de situações vinculadas a ele. $\bigcirc 110$ ponto da "Declaração de Amsterdam" dizia: "Uma situação construída é um meio de aproximação do Urbanismo Unitário e o Urbanismo Unitário é a base indispensável para o desenvolvimento da construção de situações, tanto no jogo como na seriedade, em uma sociedade mais livre" (IS, n. 2, 2004, p. 62). Dos onze pontos da Declaração, o Urbanismo Unitário está presente nominalmente em cinco deles e ainda se faz evidente em outros dois. Ou seja, de fato o Urbanismo Unitário mostrou-se, em determinado momento, como possibilidade de agregar a totalidade das propositivas prático-teóricas situacionistas. ${ }^{14}$

O texto O Urbanismo Unitário no final dos anos 1950 (IS, n. 3, 2004, p. 75) procura, de algum modo, retirar das mãos de Constant a exclusividade das ideias e das propostas sobre o Urbanismo Unitário. Nesse sentido, não parecem ocasionais as afirmações de que o Urbanismo Unitário nasce entre os camaradas que formaram a sessão italiana da IS, bem como não parecem nada ocasionais as duras críticas ao funcionalismo. Nesse texto, sem autoria declarada, fica clara ainda a tentativa de recolocar o Urbanismo Unitário não como um projeto urbanístico, mas como uma crítica ao urbanismo: "Em primeiro lugar, o Urbanismo Unitário não é uma doutrina, mas sim uma crítica do urbanismo" (IS, n. 3, 2004, p. 75) - fato que destoa profundamente das formulações de Constant, muito mais voltadas a um projeto urbanístico.

Esse texto, em verdade, antecipa uma concepção ainda mais crítica sobre o urbanismo, que se implantará na IS pouco tempo depois. Nessa concepção, já nesse texto da revista n. 3 (IS, 2004), é possível ver, talvez pela primeira vez e de modo bastante coerente, uma crítica ao espaço espetacular e àquilo que estou buscando chamar de "cidade como cenário":

O Urbanismo Unitário se distingue dos problemas estéticos como também dos do habitat. Opõe-se ao espetáculo passivo - princípio de nossa cultura onde a organização do espetáculo se estende mais escandalosamente na medida em que aumentam os meios de intervenção humana. No entanto as cidades se apresentam hoje como um espetáculo lamentável, um suplemento aos museus para turistas que passeiam em automóveis de cristal [...] (IS, n. 3, 2004, p. 76).

É também nesse texto que se fala, pela primeira e possivelmente única vez, em desvio arquitetônico, para afirmar a necessidade de transformação permanente no meio urbano e reiterar a necessidade de um espaço urbano lúdico, bem como para questionar, ainda que sem citar, o projeto acabado e fechado de Constant - "Nova Babilônia". Nesse sentido, a deriva adquire uma profundidade maior, ("A experiência situacionista da deriva, ao ser ao mesmo tempo meio de estudo do urbano e jogo, marcha no mesmo sentido do Urbanismo Unitário" [IS, n. 3, 2004, p. 77]) e passa a ser uma constante, que se coloca inclusive como proposta para impedir a fixação de pessoas em certos pontos da cidade. Aqui, a noção de Urbanismo Unitário aparece como síntese de um projeto de civilização do ócio e do jogo: "Os urbanistas do século XX terão que construir aventuras" (IS, n. 3, 2004, p. 78).

O debate em torno do Urbanismo Unitário continuou sendo travado dentro da IS e pode ser visto em relatos, ainda na revista n. 3 (IS, 2004), sobre a terceira conferência da IS realizada em Munique. Constant, ao dar o informe sobre a criação da oficina de Urba-

14 “O Urbanismo Unitário está no centro das preocupações da IS" (IS, n. 3, 2004, p. 75). 
nismo Unitário na Holanda é questionado sobre o dilema entre investigações individuais e o projeto coletivo da IS: a "delegação italiana pede algumas precisões sobre o programa concreto da 'oficina de investigações para o Urbanismo Unitário'; os inquieta a autonomia que pode tomar o movimento e (apoiados neste ponto por Jorn) a perigosa especialização que corre o risco de adquirir" (IS, n. 3, 2004, p. 79). As críticas ao Urbanismo Unitário tomam corpo, e o pensamento e a ação situacionista vão rumando no sentido da crítica ao urbanismo, seja qual for.

A revista n. 3 (IS, 2004) segue recheada pelo debate em torno do Urbanismo Unitário realizado na Terceira Conferência de Munique. Constant segue enfático ao defender a centralidade do Urbanismo Unitário, bem como sua oficina de investigações. Nos documentos da conferência, Debord traça uma poderosa crítica aos membros dessa oficina, classificando-os de reformistas: "A posição que sustentam quanto ao segundo ponto é puramente reformista" (IS, n. 3, 2004, p. 83). O debate segue em torno das possibilidades e condições do Urbanismo Unitário e vai adquirindo uma conotação cada vez mais crítica em relação a ele:

○ Urbanismo Unitário não é uma concepção da totalidade, não deve chegar a sê-lo. É um instrumento [...] $\bigcirc$ U.U. [Urbanismo Unitário] é central na medida em que está no centro da construção de todo um entorno. Não pode pensar-se em determinar e dominar um tipo de vida mediante esta visão teórica, nem mediante sua aplicação. Será uma espécie de dogmatismo idealista. A realidade mais complexa e rica compreende todas as relações destes tipos de vida e de seus cenários. Aqui está o terreno adequado a nossos desejos atuais, aquele em que temos que intervir (IS, n. 3, 2004, p. 83).

André Frankin também se colocava criticamente em relação ao caminho que o Urbanismo Unitário vai galgando sob a tutela de Constant: "A criação coletiva do Urbanismo Unitário está baseada, naturalmente, em uma concepção de totalidade. Mas quando se confunde isto com uma atividade que compreenda a totalidade se excedem seus poderes reais e tal proposta está condenada a total inatividade" (IS, n. 3, 2004, p. 84).

A revista n. 3 (IS, 2004) da IS expõe a luta travada entre os situacionistas em torno das possibilidades e formas de realização do Urbanismo Unitário. Se nela ficam evidentes, pela primeira vez, os limites e as poderosas críticas a essa proposta, também nela se reafirmam as necessidades de manter o Urbanismo Unitário no centro das preocupações situacionistas. No texto Informe Inaugural, escrito por Constant, evidencia-se o prosseguimento da batalha em torno do tema, concluindo-se que: "Não devemos desistir [do Urbanismo Unitário] sem ter examinado em comum as possibilidades já existentes para as experiências práticas" (IS, n. 3, 2004, p. 85). Nesta mesma edição outros situacionistas afirmam: "Esta atitude idealista [Urbanismo Unitário] é o maior perigo que corremos atualmente” (IS, n. 3, 2004, p. 86).

A revista n. 3 (IS, 2004) ainda teria mais três textos que abordavam direta ou indiretamente a questão do Urbanismo Unitário: Correção para adoção dos onze pontos de Amsterdam; Primeira programação da sessão holandesa; e Outra cidade para outra vida. Estes dois últimos contam com a assinatura de Constant. Neste último, Constant mais uma vez declara seu carinho pelo funcionalismo e fala abertamente em um "novo funcionalismo", em que depois de estabelecidas as funções sucederia o jogo (IS, n. 3, 2004, p. 97). É também neste texto que Constant expõe abertamente seu projeto sobre a "Nova Babilônia": 
A cidade futura será concebida como uma construção contínua sobre pilares ou como um sistema ampliado de construções diferentes em que estariam suspensos os locais de habitação, lazer etc., e locais destinados à produção e distribuição, deixando o solo livre para o trânsito e as reuniões públicas. A aplicação de materiais ultraleves e isolantes, como os que surgem atualmente, possibilitará uma construção leve com suportes bem espaçados. De tal modo que se poderá construir uma cidade com várias camadas: subsolo, térreo, andares, terraços, cuja extensão pode variar da equivalente a um bairro atual até uma metrópole. Convém notar que numa cidade desse tipo a superfície construída será de 100\% e a superfície livre será de $200 \%$ (chão e os terraços), ao passo que nas cidades tradicionais esses valores são da ordem de 80\% e 20\%; e na cidade verde, essa relação pode, no máximo, ser invertida. Os terraços formam um terreno ao ar livre que se estende sobre toda a superfície da cidade e pode ser transformado em quadras de esporte, campos de aterrissagem para aviões e helicópteros e em espaços para a vegetação. Serão de fácil acesso por meio de escadas e elevadores. Os diferentes andares serão divididos em espaços que se comunicam, com sistema de climatização, oferecendo a possibilidade de criar uma variação infinita de ambiências, facilitando a deriva dos moradores e seus frequentes encontros programados. As ambiências serão regular e deliberadamente mudadas, com a ajuda de todos os dispositivos técnicos, por equipes de criadores especializados, que serão situacionistas profissionais (IS, n. 3, 2004, p. 97).

O fragmento acima integra o último texto destinado ao Urbanismo Unitário dentro da IS. As contradições dentro de seu programa de Urbanismo Unitário chegam ao limite e já não podem ser suportadas dentro do projeto de revolução total situacionista. Além de tecnocrata, Constant reforça muitos dos problemas a serem combatidos pelo grupo, entre os quais a necessidade de abolir a figura do arquiteto e de sua obra, bem como toda e qualquer criação de ordem individual e ainda o fim da profissão, seja ela qual for, pois sua existência impõe a especialização. No texto Outra cidade para outra vida (IS, n. 4, 2004) o autor vai radicalmente à direção oposta, ao propor situacionistas profissionais, ao propor um projeto acabado de cidade e pronto para ser aplicado sobre tudo e todos. Seu projeto acabado e autoral até o último centímetro impede toda e qualquer criação e improviso. A forma superacabada de seu projeto, no limite, põe fim às tendências labirínticas - inviabiliza a deriva. Constant ainda assina mais um texto "Descrição da zona amarela" (IS, n. 4, 2004), mas sua expulsão se faz eminente.

A Nova Babilônia de Constant parte do Urbanismo Unitário e chega ao espaço totalitário. Seu projeto é ainda pior que o funcionalismo, por ser justamente sua reiteração - mais do mesmo. ${ }^{15}$ Constant não quis pôr fim ao planejamento urbano ou à obra arquitetural, quis realizá-la a seu modo e pretensiosamente de forma definitiva.

15 Vale lembrar que a trajetória de Constant antes da IS passa pelo grupo Cobra, mas também por uma influência dos ideais da Arquitetura Moderna e do funcionalismo. Ele chega a publicar, em 1952, junto com Aldo Van Eyck (membro do Team X, de que tratarei em nota posterior), o manifesto "Por um colorismo espacial", em favor de uma ação conjunta entre as artes plásticas e a arquitetura. "Constant falava em rede e espaço dinâmico, termos que os membros do Team X também usavam na mesma época” (Jacques, 2003, p. 28). Jappe (2004, p. 111) compartilha desse meu entendimento, chegando a dizer que o projeto da Nova Babilônia não é em si tão diferente da Cidade radiosa de Le Corbusier. 
A revista n. 5 da IS (2004) marca a passagem definitiva das propositivas referentes ao Urbanismo Unitário à crítica voraz do urbanismo. Inevitavelmente, o debate interno do grupo que levou a essa mudança de perspectiva tornou impossível a permanência de Constant na IS. ${ }^{16}$ Foi durante as conversações da IV Conferência da IS que Constant não só foi retirado do "comando" da Oficina de Urbanismo Unitário, como foi retirado (em verdade se retirou) da IS.17 Entretanto, ainda na revista n. 5 (IS, 2004), é possível ver o último esforço do grupo para manter os trabalhos de pesquisa sobre Urbanismo Unitário, que foram delegados a um discreto participante, A. Kotányi. Esse esforço não dura mais que alguns poucos meses e logo a Oficina de Urbanismo Unitário é definitivamente desfeita. Se, nas revistas n. 4 e n. 5 da IS (2004) o debate em torno do urbano e do urbanismo não foram centrais (em verdade pouco existiram, ao menos nos textos publicados), na revista n. 6 (IS, 2004) a questão do urbano vem à tona com força e radicalismo. $\bigcirc$ primeiro de seus textos dedicados ao tema - Críticas ao urbanismo - evidencia, já no título, a guinada. "O projeto de um urbanismo mais moderno, mais progressista, concebido como uma correção da especialização urbanística atual é tão falso como a sobrestimação do momento de tomar o poder no projeto revolucionário" (IS, n. 6, 2004, p. 174). E assim segue:

[...] o urbanismo é forçosamente inimigo de todas as possibilidades da vida urbana da nossa época. É um fragmento do poder social que pretende representar uma totalidade coerente e tende a se impor como explicação e organização total, não fazendo mais que mascarar a totalidade social real que o foi produzindo e que ele o conserva (IS, n. 6, 2004, p. 174).

Nota-se um ataque direto à possibilidade de propor modelos urbanísticos - sejam lá quais forem - inclusive a "Nova Babilônia". Aliás, parece-me que, ao citar a tentativa de representar a totalidade de forma coerente, o texto faz menção, ainda que velada, ao projeto de Constant. Dizem os situacionistas nesse novo momento de pensar o urbano, negando a possibilidade do Urbanismo Unitário:

Se aceitarmos esta especialização do urbanismo, nos colocaremos a serviço da mentira urbanística e social existentes, do estado, para realizar um dos múltiplos urbanismos "práticos" possíveis, porém o único urbanismo prático possível para nós, o que temos chamado de Urbanismo Unitário, é abandonado neste momento, pois exige a criação de condições de vida completamente diferentes (IS, n. 6, 2004, p. 174).

16 De modo geral, o grupo holandês foi sendo expulso. Já na revista n. 4 (IS, 2004), dois membros da sessão holandesa da IS - Alberts e Oudejans - foram expulsos, depois de aceitarem participar da construção de uma igreja em Volendam.

17 Sobre a saída de Constant, foi publicada a seguinte nota na revista n. 5: "[...] Constant se encontra em oposição à IS, porque se ocupa prioritariamente, quase exclusivamente, de questões de estrutura de alguns conjuntos do Urbanismo Unitário, depois que outros situacionistas rechaçaram que o estado presente de um projeto semelhante seja necessário por acento nos conteúdos (do jogo, da criação livre, da vida cotidiana). As teses de Constant valorizam portanto os técnicos de formas arquitetônicas com respeito a toda uma cultura de investigação global. E a simples igualdade de tratamento, enquanto à conduta exigida uns aos outros the parece desproporcionalmente severa. Constant declarou então, no mesmo mês de junho, que estava em desacordo com a disciplina da IS e queria recuperar sua liberdade por um tempo que os acontecimentos seguintes determinariam. Nós respondemos que, deixando de lado toda hostilidade ou demérito, o sentido da arma prática que nós temos afirmado a longo prazo com as rupturas registradas na IS permitiam só eleger imediatamente entre uma demissão definitiva ou a renúncia a essa forma de pressão. Constant escolheu abandonar a IS" (IS, n. 5, 2004, p. 142). 
$\bigcirc$ avanço do pensamento coletivo situacionista chega ao ponto de compreender o equívoco em propor um projeto de cidade, quando a verdadeira questão é propor um novo projeto de realização da vida.

Simultaneamente à sua eliminação dentro da IS, o Urbanismo Unitário passara a figurar na lista das possibilidades urbanísticas a serem aplicadas desde então. Alguns projetos de Urbanismo Unitário chegaram a ser postos em curso na então Alemanha Ocidental, especificamente no vale do Ruhr; chegou-se ao ponto de se propor o lançamento de um laboratório de Urbanismo Unitário em Essen (no lugar onde funcionava a galeria de arte Van de Loo), o que gerou uma série de críticas aos antigos membros holandeses, mais notadamente a Constant. Em suma, o Urbanismo Unitário cai em seu definitivo processo de decomposição e passa a ser consumido como mais um produto urbanístico derivado do funcionalismo e passível de ser aplicado à sociedade capitalista, fato que é motivo de rechaço por parte dos situacionistas que se negam a dialogar com qualquer uma das frentes de ação nesse sentido (como mencionado, surgiram algumas na Alemanha e também na Bélgica). ${ }^{18}$

A contestação da sociedade atual em seu conjunto é o único critério para a liberação autêntica no âmbito das cidades, como em qualquer outro âmbito da atividade humana. De outra forma, as "melhoras", os "progressos", sempre estarão destinados a ingressar no sistema, a aperfeiçoar o condicionamento que deve ser destruído no urbanismo e em toda parte. (IS, n. 6, 2004, p. 175)

O texto Crítica do Urbanismo (IS, n. 6, 2004) marca a passagem definitiva do projeto de Urbanismo Unitário à crítica ao urbanismo, não só dentro da IS, mas também no movimento do pensamento de seus principais teóricos, por assim dizer. Tanto Raoul Vaneigem como Guy Debord, em seus livros, traçaram observações e críticas ao urbanismo como momento de espacialização do poder e da forma mercadoria; como um dos mais poderosos agentes inviabilizadores da vida cotidiana liberada. Não por acaso, Debord (1997) tem um capítulo em seu livro A sociedade do espetáculo, exclusivamente dedicado ao tema: "Planejamento do espaço".

Se a revista n. 3 da IS (2004) foi notadamente marcada pelo debate sobre o Urbanismo Unitário, a n. 6 (2004) é definitiva ao traçar a crítica ao urbanismo, com três textos diretamente voltados ao tema; e se Constant ocupava um lugar chave nas propositivas sobre o Urbanismo Unitário, agora Raoul Vaneigem e Atilla Kotanyi tomam a frente na crítica ao urbanismo. $\bigcirc$ urbanismo agora é entendido como atrelado ao espetáculo e como parte importante da organização capitalista. ${ }^{19}$ As considerações sobre o tema, nesta revista, são tão poderosas que pouco se escreve a esse respeito nas revistas seguintes. Depois disso, ao que tudo indica, o entendimento do grupo se estabelece de acordo com o que foi escrito na IS, n. 6 (2004).

18 próprio Constant levou adiante a ideia do Urbanismo Unitário, aproximando-se dos capitalistas alemães para efetivar seu projeto.

19 "O urbanismo não existe: não é mais do que uma ideologia no sentido de Marx. A arquitetura existe realmente, como a coca-cola: é uma produção recheada de ideologia que satisfaz falsamente uma falsa necessidade, porém é real. Entretanto, o urbanismo é, como a ostentação publicitária que rodeia a coca-cola, pura ideologia espetacular. $\bigcirc$ capitalismo moderno, que organiza a redução de toda a vida social a espetáculo, é incapaz de oferecer outro espetáculo que o da nossa alienação. Seu sonho urbanístico é seu mestre de obras" (IS, n. 6, 2004, p. 182). 
Em suma, o que se nota é que as propositivas em torno da cidade e do urbano dos letristas e situacionistas tomam como ponto de partida a possibilidade de intervenção direta no tecido das cidades por meio de um projeto de urbanismo, o Urbanismo Unitário. Todavia, essas propostas urbanísticas de planejamento urbano, mesmo as mais ousadas e revolucionárias, foram descartadas ao longo do projeto de transformação total da vida cotidiana estabelecida como meta e finalidade pelos situacionistas. Ao longo de seus debates e publicações, esse grupo consolida uma postura inteiramente crítica de negação dos projetos e dos planejamentos urbanísticos e estabelece a crítica ao urbanismo como base de suas discussões sobre a cidade, a vida cotidiana e a revolução.

\section{Referências}

DEBORD, G. A sociedade do espetáculo. Rio de Janeiro: Contraponto, 1997. Potlatch (1954-1957). Paris: Gallimard, 1996.

Relatório sobre a construção de situações e sobre as condições de organização e de ação da tendência Situacionista Internacional. In: CONFERÊNCIA DE FUNDAÇÃO DA INTERNACIONAL SITUACIONISTA. Cosio d'Arroscia, 1957.

FELGUERAS [coletivo]. Ese imbécil llamado Sartre: antología de insultos publicados en Internationale Situationniste. Madri: Ediciones La Felguera, 2008.

HUIZINGA, J. Homo Ludens. São Paulo: Perspectiva, 2005.

IS. INTERNACIONAL SITUACIONISTA. Textos íntegros en castellano de la revista Internationale Situacionniste (1958-1969). Madrid: Traficantes de Sueños, 2004.

. Sessão inglesa. La Rioja: Pepitas, 2007.

. INTERNAZIONALE SITUAZIONISTA. Sessão italiana. La Rioja: Pepitas, 2007.

. INTERNATIONALE SITUATIONNISTE. Paris: Arthème fayard, 1997.

JACQUES, P. B. (Org.). Apologia da deriva: escritos situacionistas sobre a cidade. Rio de Janeiro: Casa da Palavra, 2003.

JAPPE, A. L'Avant-Garde Inacceptable: Reflexions sur Guy Debord. Paris: Éditions Lignes, 2004.

Guy Debord. Paris: Via Valeriano/Editions Sulliver, 1998.

JORN, A. Pour la forme. Paris: Allia, 2001.

MAGALHÃES, F. L. B. M. Ideias provisórias para tempos provisórios: a trajetória da Internacional Situacionista e apontamentos para seu lugar na geografia. Dissertação (Mestrado em Geografia Humana) - Faculdade de Filosofia, Letras e Ciências Humanas, Universidade de São Paulo, São Paulo, 2011. 
SILVA, F. E. Aproximar sem reduzir: as derivas e a pesquisa de campo em geografia urbana. Geousp - Espaço e Tempo, São Paulo, n. 15, p. 139-149, 2004.

VANEIGEM, R. A arte de viver para as novas gerações. São Paulo: Conrad, 2002.

VASCONCELLOS, R. P. Cidade-máquina, projeto e utopia: ensaio de crítica espacial ao construtivismo russo. Trabalho de Conclusão de Curso (Geografia) - Faculdade de Filosofia, Letras e Ciências Humanas, Universidade de São Paulo, São Paulo, 2015. 